\title{
Inhibition of growth rate and cylindrospermopsin synthesis by Raphidiopsis raciborskii upon exposure to macrophyte Lemna trisulca (L)
}

\author{
Kornelia Duchnik $^{1} \cdot$ Jan Bialczyk ${ }^{1} \cdot$ Ewelina Chrapusta-Srebrny $^{1} \cdot$ Beata Bober $^{1}$
}

Accepted: 22 February 2021 / Published online: 12 March 2021

(c) The Author(s) 2021

\begin{abstract}
Impact of macrophyte Lemna trisulca on the growth rate and synthesis of cylindrospermopsin (CYN) by cyanobacterium Raphidiopsis raciborskii was determined. The presence of $L$. trisulca inhibited the biomass accumulation of the cyanobacterium by $25 \%$ compared to the control during co-cultivation. The simultaneous cultivation of these organisms slightly affected the inhibition of macrophyte growth rate by $5.5 \%$ compared to the control. However, no morphological changes of $L$. trisulca after incubation with cyanobacteria were observed. It was also shown that the long-term (35 days) cocultivation of $R$. raciborskii and $L$. trisulca led to a decrease in CYN concentration in media and cyanobacterial cells by 32 and $38 \%$, respectively, compared to the values obtained for independent cultivation of cyanobacterium. Excessive absorption of phosphate ions by L. trisulca from the medium compared to nitrate ions led to a significant increase in the nitrate: phosphate ratio in the media, which inhibits the development of cyanobacterium. The obtained results indicate that L. trisulca in the natural environment may affect the physiology of cyanobacteria. The presented study is the first assessment of the allelopathic interaction of macrophyte and R. raciborskii.
\end{abstract}

Keywords Allelopathy $\cdot$ Biomass accumulation $\cdot$ Cylindrospermopsin $\cdot$ Lemna trisulca $\cdot$ Raphidiopsis raciborskii

\section{Introduction}

In aquatic ecosystems, macrophytes and phytoplankton represent a group of primary producers. Macrophytes play an essential role in the nutrient cycling in the environment through their significant accumulation in submerged roots or leaves, thus limiting the availability of necessary elements for the development of phytoplankton (Pott and Pott 2003). They also provide shelter for invertebrates, macrophages, zooplankton and young fish (Mulderij et al., 2007). The metabolism of macrophytes affects the physicochemical properties of water, including changes in concentration of oxygen, inorganic carbon or $\mathrm{pH}$ (Caraco and Cole, 2002). Chemical interactions between aquatic organisms attract the attention of researchers from around the world (Pflugmacher, 2002). It is believed that using macrophytes might be an effective, safe

Kornelia Duchnik

kornelia.zabaglo@uj.edu.pl

1 Department of Plant Physiology and Development, Jagiellonian University, Gronostajowa 7, 30-387 Kraków, Poland and ecofriendly method for controlling and removing toxic cyanobacterial blooms from the water.

So far, numerous studies have been carried out on the effects of allelopathic compounds released by macrophytes into the water environment on cyanobacteria (Gross, 1999; Hong et al., 2011; Nakai et al., 2012, Mohamed 2017). Some of them, such as tellimagrandin II, pyrogallic or gallium acids synthesized by Myriophyllum spicatum significantly impair the photosynthetic activity of Anabaena sp. and Microcystis aeruginosa (Leu et al., 2002; Zhu et al., 2010). Oxidative damage, including loss of membrane integrity and inhibition of protein synthesis, is also an important mechanism of toxicity of plant allelochemicals against M. aeruginosa (Lu et al., 2016; Tazart et al., 2020). However, allelopathic products can simultaneously stimulate a significant increase in the activity of antioxidant enzymes, e.g., superoxide dismutase and catalase, suggesting their involvement in the elimination of oxidative stress in cyanobacteria (Hong et al., 2008; Lu et al., 2016; Zhang 2015; Hua et al., 2018; Kang et al., 2020; Tazart et al., 2020). Additionally, various phenolic compounds, fatty acids, terpenoids and asarone synthesized by aquatic plants reduce the biomass of cyanobacteria and induce changes in their cell and colonial morphology (Nakai et al., 2000; Rojo 
et al., 2013; Hang, 2017; Mowe et al., 2019; Tazart et al., 2019).

Although Raphidiopsis raciborskii is the main producer of the cytotoxic cylindrospermopsin (CYN) documented in water bodies all over the world (Rzymski and Poniedziałek 2014; Kleinteich et al., 2014), there is no information in the literature on the allelopathic effect of macrophytes occupying the same ecological niche on its physiology and biochemistry. CYN, in animal organisms, inhibits protein synthesis, causes damage to cell nuclei, increases the concentrations of reactive oxygen species, induces DNA fragmentation (Lankoff et al., 2007) as well as affects organs such as liver (Terao et al., 1994) and kidneys (Norris et al., 2001). An additional risk is the accumulation of CYN in the food chain that can pose a great threat to all organisms, including humans. This explains the growing interest in recent years in searching for methods to reduce $R$. raciborskii blooms and thus eliminate CYN from the environment.

Therefore, Lemna trisulca, which occurs in the natural environment in direct contact with cyanobacterium and cyanotoxin was selected for the study. This macrophyte effectively reduces the development of other cyanobacterium, Anabaena flos-aquae, and the concentration of synthetized anatoxin-a (Kaminski et al., 2015), what additionally confirms this choice. In order to assess the influence of L. trisulca on limiting the development of $R$. raciborskii and the level of CYN, we examined changes in biomass accumulation, concentrations of nitrogen and phosphorus in media and synthesis of cylindrospermopsin by cyanobacterium during long-term cultivation of these two organisms. It is assumed that the results can be used in the future to reduce the formation of cyanobacterium blooms in water bodies and to bioremediate the produced toxin.

\section{Materials and methods}

\section{Growth conditions of the test organisms}

To the experiments we used the cultures of Raphidiopsis raciborskii (Wołoszyńska) Aguilera, Berrendero Gómez, Kaštovský, Echenique \& Salerno comb. nov. strain CS-505/7 obtained from the Australian Algae Culture Collection (Australia) and Lemna trisulca strain LT-FR 1 collected from the natural environment and brought into pure, sterile culture in our laboratory. Both organisms were cultivated in separate Erlenmeyer flasks containing BG-11 medium (Rippka et al. 1979 ) in a phytotron (Bolarus S-711S/P, Poland) at $20 \pm 1^{\circ} \mathrm{C}$, with $80 \%$ humidity under $50 \mu \mathrm{mol} \mathrm{m} \mathrm{m}^{-2} \mathrm{~s}^{-1}$ photosynthetically active radiation (PAR) with a light/dark period of 12/12 h. Each flask was shaken regularly every day.

\section{The experimental procedure}

The biweekly $R$. raciborskii cultures were transferred to $50 \mathrm{~mL}$ of falcons and centrifuged $(10,000 \mathrm{~g} \times 5 \mathrm{~min})$. Cyanobacterial cells were then suspended in a small volume of fresh medium and shaken on SK-0330-PRO shaker (Chemland, Poland). The concentrated cell suspension of $3 \mathrm{~mL}$ was added to the $100 \mathrm{~mL}$ sterile Erlenmeyer flasks filled with $40 \mathrm{~mL}$ of aerated BG-11 medium for cultivation of (a) cyanobacterium, and (b) cyanobacterium with macrophyte. To the latter ones as well as to the flasks planned for the cultivation of the macrophyte itself, $1 \mathrm{~g}$ fresh weight (fw) of L. trisulca was added. Each experimental series was prepared in five independent replicates. The initial ratio of the dry weight of macrophyte and cyanobacterium was 26: $1(\mathrm{w} / \mathrm{w})$. The experiment was conducted under the physical conditions described above, and the samples were taken in $5,10,15,20$ and 35 day of cultivation. A specially prepared set was used to separate the medium, cyanobacterium and macrophyte after cultivation. It was consisted of: a vacuum flask connected to a vacuum pump, a Büchner funnel with Whatman's previously weighed filter and a $2 \mathrm{~mm}$ metal sieve. During the separation of the two-species culture, first L. trisulca was stopped on the strainer, then $R$. raciborskii cells were accumulated on Whatman's filter, and finally, the medium was collected in the flask. After separation of all components, the set was rinsed with $10 \mathrm{~mL}$ of Milli $\mathrm{Q}$ water for removal of unbound CYN from the surface of the plant and cyanobacterial cells.

\section{Measurements}

\section{Biomass accumulation}

$L$. trisulca and $R$. raciborskii were subjected to a freezedrying process to obtain a dry weight. The dry weight of cyanobacterium was determined using the weight of empty Whatman's filter and respective that with embedded cyanobacteria cells.

\section{Concentration of CYN}

CYN was extracted and purified from the cyanobacteria cells, media and plant tissues as described by Meriluoto and Codd (2005) with some modifications. The toxin was quantified using a High-Performance Liquid Chromatography (HPLC) Waters system consisting of a 600E gradient pump, a 717 plus autosampler, a 996 photodiode array (PDA) detector, a Millenium ${ }^{32}$ SS Software with PDA option, a Jetstream 2 plus column thermostat and a reverse phase column Phenomenex Gemini $(250 \times 4.6 \mathrm{~mm} ; 5 \mu \mathrm{m})$ kept at $35^{\circ} \mathrm{C}$. The PDA range was $210-400 \mathrm{~nm}$ with a fixed wavelength of $262 \mathrm{~nm}$. The gradient mobile phase consisted 
of water/acetonitrile (both with $0.05 \%$ trifluoroacetic acid) changed from 100 to $70 \%$ water in $20 \mathrm{~min}$ at a flow rate of $1.0 \mathrm{~mL} \mathrm{~min}^{-1}$. CYN was identified and quantified by comparing of the UV-spectra determined for the standard.

\section{pH determination}

Values of media $\mathrm{pH}$ were determined using a glass $\mathrm{pH}$ microelectrode (InLab 423, Mettler Toledo, Switzerland).

\section{Concentration of nitrate and phosphate ions}

The concentration of nitrate and phosphate ions in media were carried out with using the DX600A ion chromatograph (Dionex, USA) containing AS40 autosampler and ED50 detector, the AS9-HC column $(4 \times 250 \mathrm{~mm})$ and a liquid phase consisting of a $9 \mathrm{mM}$ solution of $\mathrm{Na}_{2} \mathrm{CO}_{3}$. The PeakNet program was used for analyzing results.

\section{Chemicals}

All reagents used for the experiment were purchased from Sigma-Aldrich (St. Louis, MO, USA). The commercial standard of CYN (purity > 95\%) was supplied from SigmaAldrich (St. Louis, MO, USA). Ultrapure grade water (Milli-Q water) was obtained from Millipore (Bradford, MA, USA).

\section{Statistical analysis}

The reported data were expressed as the mean \pm SD of five replicates. All the obtained results were subjected to oneway or two-way ANOVA, and all the means were tested for significant differences $(p<0.05)$ with Tukey's test. Statistical analyses were made using STATISTICA 13 software.

\section{Results}

\section{Biomass accumulation}

Short-term (up to 10 days) simultaneous cultivation of cyanobacterium and macrophyte did not affect the plant's biomass accumulation compared to the control $(F=0.35$, $p=0.56$ ). After 20 and 35 days of co-cultivation, a decrease in L. trisulca biomass accumulation by $3 \%(F=1.95$, $p=0.18)$ and $5.5 \%$ were shown $(F=6.79, p=0.02)$, respectively (Fig. 1). During the 20 days of the experiment, no statistically significant changes in the growth of the cyanobacterial biomass were observed $(F=0.06, p=0.81)$. However, on day 35 of cultivation the presence of $L$. trisulca inhibited the development of $R$. raciborskii. The final dry weight of cyanobacterial cells represented $75 \%$ of the

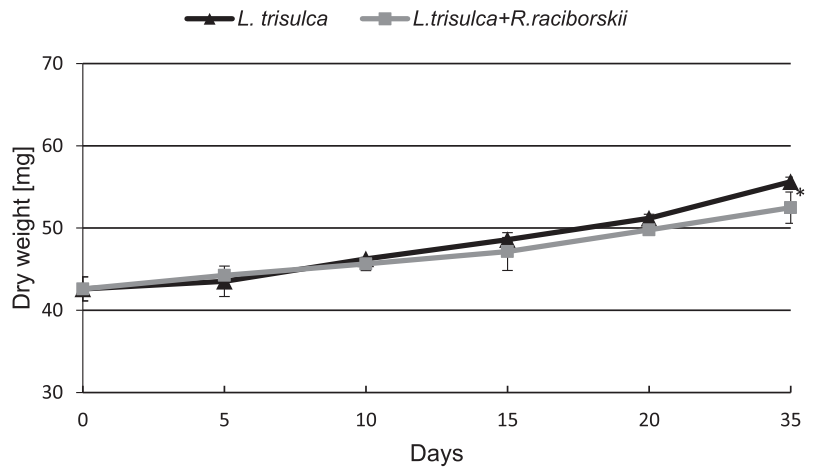

Fig. 1 Changes of the dry weight of L. trisulca cultivated individual or with $R$. raciborskii. Data are expressed as mean $\pm \mathrm{SD}(n=5)$, *significant difference from control at $p<0.05$

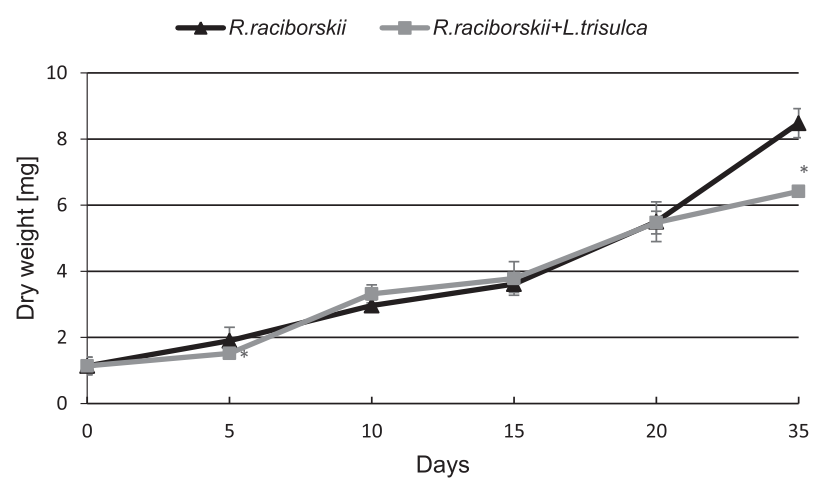

Fig. 2 Changes of the dry weight of $R$. raciborskii cultivated individual or with $L$. trisulca. Data are expressed as mean $\pm \operatorname{SD}(n=5)$, *significant difference from control at $p<0.05$

value determined for independent cultivation $(F=123.72$, $p<0.05$ ) (Fig. 2).

\section{CYN concentration in the medium, plant tissues and cyanobacterial cells}

The initial CYN concentration in the medium was $0.4 \mu \mathrm{g} \mathrm{mL}^{-1}$. After 35 days of the experiments, toxin concentration in the medium of simultaneous cultivation reached only $68 \%$ of the value detected in the medium where cyanobacteria grew separately $(F=45.73, p<$ $0.05)$ (Fig. 3). Interestingly, no CYN was detected in $L$. trisulca tissues (Fig. 4). The initial concentration of CYN in $R$. raciborskii cells was $0.8 \mu \mathrm{g} \mathrm{mg}^{-1} \mathrm{fw}$ and it increased in time. During the first 10 days, the changes in concentration level did not differ significantly between separate cultures of cyanobacterium and cyanobacterium with macrophyte $(F=2.73, p=0.12)$ (Fig. 5). Then the CYN intracellular content in co-cultivating cyanobacterium decreased and on the 35th day was lower by $38 \%$ compared to separate cultivation of cyanobacterium $(F=$ 924.53, $p<0.05)$. 


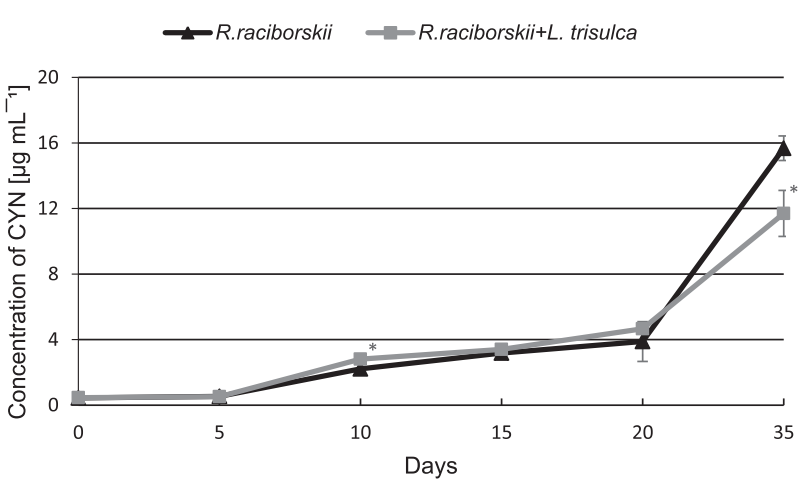

Fig. 3 The concentration of CYN in the medium during 35 days of independent cultivation of $R$. raciborskii or simultaneous with $L$. trisulca. Data are expressed as mean $\pm \operatorname{SD}(n=5)$, *significant difference from control at $p<0.05$

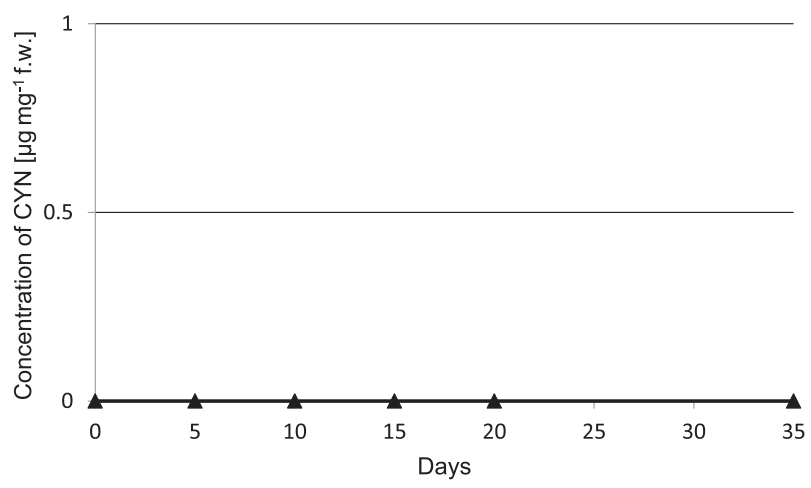

Fig. 4 The concentration of CYN in L. trisulca tissues during 35 days cultivation with $R$. raciborskii. Data are expressed as mean $\pm \mathrm{SD}(n=$ $5)$, *significant difference from control at $p<0.05$, fw fresh weight

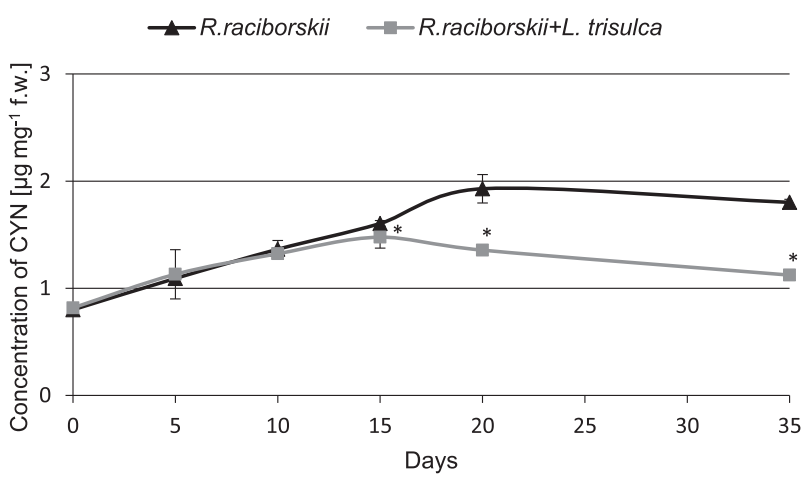

Fig. 5 The concentration of $\mathrm{CYN}$ in cyanobacterial cells during 35 days of independent cultivation of $R$. raciborskii or simultaneous with $L$. trisulca. Data are expressed as mean $\pm \operatorname{SD}(n=5), *$ significant difference from control at $p<0.05$, $f w$ fresh weight

\section{$\mathrm{pH}$ value in the medium}

The initial $\mathrm{pH}$ value of 7.5 in the control medium (without organisms) did not change significantly during the whole experiment. The cultivation of $L$. trisulca, $R$. raciborskii and both organisms simultaneously stimulated the increase

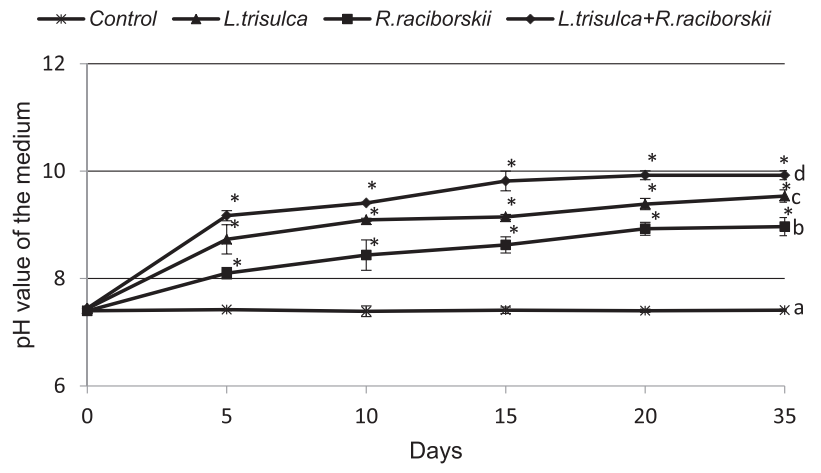

Fig. 6 Changes of $\mathrm{pH}$ value of the medium over 35 days of cultivation of the control (without any organisms) (a), R. raciborskii (b), L. trisulca $(\mathbf{c})$ and $L$. trisulca with $R$. raciborskii $(\mathbf{d})$. Data are expressed as mean $\pm \operatorname{SD}(n=5), *$ significant difference from control at $p<0.05, f w$ fresh weight

of the $\mathrm{pH}$ of the media during the experiment. In the experimental series tested, the highest $\mathrm{pH}$ values were found on the last day of the incubation. After 35 days, the $\mathrm{pH}$ value of the medium where $R$. raciborskii, L. trisulca or both organisms were cultivated increased by $1.46(F=$ $855.91, p<0.05), 2.00(F=3078.48, p<0.05)$ or 2.50 units $(F=7953.73, p<0.05)$, respectively (Fig. 6).

\section{Concentration of nitrate and phosphate ions in the medium}

Significant increase in the nitrate ions concentration by $20 \%$ compared to the initial value was demonstrated in medium of all experimental series after 5 days of cultivation $(F=1311.12, p<0.05)$ (Fig. 7). On 35th day their concentration was determined at $100 \%(F=0.19, p=$ $0.67), 68 \%(F=6500.02, \quad p<0.05)$ and $78 \% \quad(F=$ $2179.26, p<0.05)$ of the initial value in the media after incubation of $L$. trisulca, $R$. raciborskii or $L$. trisulca with $R$. raciborskii, respectively. After just 5 days, the concentration of phosphate ions was reduced by $92 \%$ ( $F=$ $17224.53, p<0.05)$ and $91 \%(F=28783.57, p<0.05)$ in media containing macrophyte or macrophyte with a cyanobacterium, respectively. In contrast, no significant change was detected in the medium containing cyanobacterium $(F=1.99, p=0.20)$. Although this value decreased to $38 \%$ of the initial concentration on 35th day $(F=2320.24, p<0.05)$, it was higher than determined for the other experimental series (Fig. 8).

\section{Discussion}

\section{Biomass accumulation}

The obtained results showed that the co-cultivation of $L$. trisulca with $R$. raciborskii resulted in a slight decrease in 


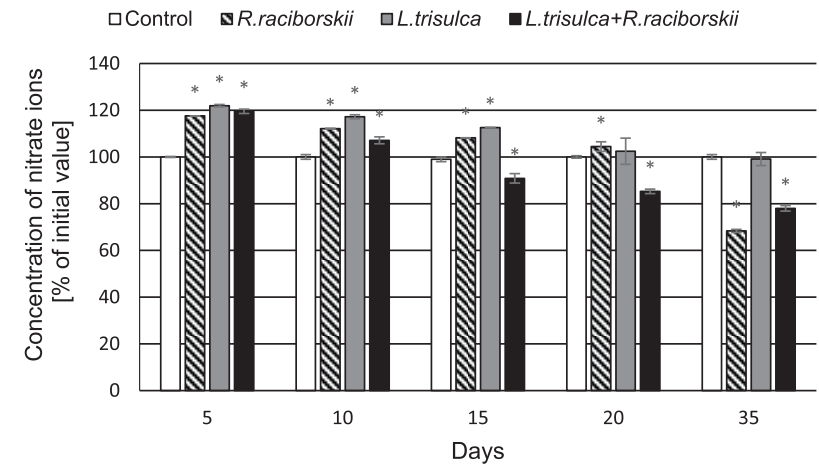

Fig. 7 The concentrations of nitrate ions in the medium over 35 days of the experiment. Data are expressed as mean $\pm \mathrm{SD}(n=5)$, *significant difference from control at $p<0.05$

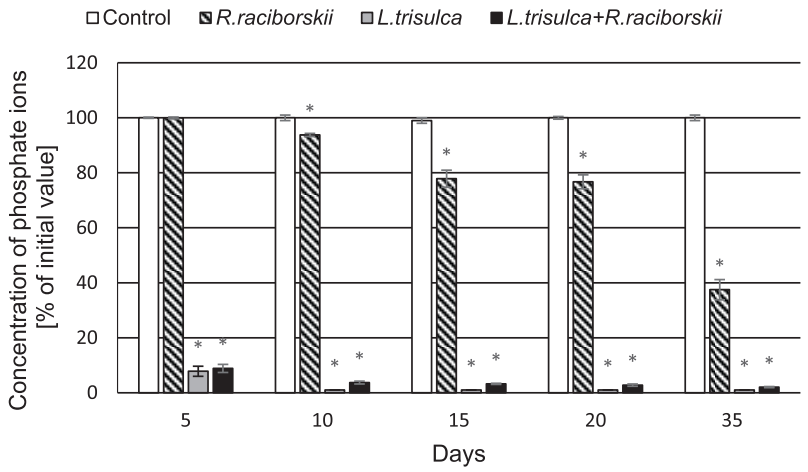

Fig. 8 The concentrations of phosphate ions in the medium over 35 days of the experiment. Data are expressed as mean $\pm \mathrm{SD}(n=5)$, *significant difference from control at $p<0.05$

plant biomass accumulation compared to control samples (Fig. 1). Such insignificant changes could be associated with the depletion of minerals in the medium or the release of secondary metabolites synthesized by cyanobacteria into the external environment. Furthermore, the tested macrophyte did not show any visible morphological changes such as chlorosis or necrosis. The simultaneous 35 days cultivation of $L$. trisulca with $R$. raciborskii resulted in a $25 \%$ reduction of the growth rate of cyanobacterial biomass compared to the data obtained for independent cultivation of cyanobacterium (Fig. 2). The similar result was presented by Kaminski et al. (2015). Long-term (32 days) cultivation of L. trisulca with Anabaena flos-aquae caused a rapid decrease of the cyanobacterium growth rate and changes in the morphological structure of its cells. Jang et al. (2007) also demonstrated a significant reduction of Microcystis aeruginosa biomass during its cultivation with $L$. japonica compared to the values achieved for separate cyanobacterial culture. Moreover, Nakai et al. (1999) provided information on the inhibition of growth rate of several cyanobacterial species such as M. aeruginosa, A. flos-aquae and Phormidium tenue during simultaneous cultivation with macrophytes Cobomba caroliniana and Myriophyllum spicatum.
The inhibition of cyanobacterial biomass accumulation may be a consequence of (a) an increase in $\mathrm{pH}$ value of the medium, (b) the appearance of a stress reaction caused by a deficiency of some ions, (c) an increase in the $\mathrm{N}: \mathrm{P}$ ratio value, or (d) the synthesis of allelopathic compounds by macrophytes and their release into the medium. After longterm cultivation of $L$. trisulca with $R$. raciborskii, a very high level of CYN was determined in the media $(11.7 \mu \mathrm{g}$ $\mathrm{mL}^{-1}$ ) (Fig. 3), whereas the tested macrophyte did not show any visible morphological changes such as chlorosis or necrosis. This result suggests that during co-cultivation, macrophyte resistance to CYN produced by cyanobacterium is much higher than in conditions when a pure toxin is added into the medium (Flores-Rojas et al., 2015, Santos et al., 2015). The observed increase in plants resistance during simultaneous cultivation might be caused by (a) an additional production of other types of toxins by the tested cyanobacterial species that could exert an opposite effect to CYN (Holland and Kinnear, 2013), (b) the synthesis of various metabolites by cyanobacteria that regulate the macrophyte growth rate and eliminate the harmful effects of CYN, (c) the release of primary metabolites that the plant may have used, (d) the synthesis of plant secondary metabolites with a protective function, or (e) the potential effect of light shading by L. trisulca (Dziga et al., 2007; Hong et al., 2009). Kaminski et al. (2015) did not find significant differences in the macrophyte biomass accumulation during cultivation of L. trisulca with A. flos-aquae for 32 days and obtained similar results to ours. In contrast, opposite data were obtained by Jang et al. (2007), who after 12 days of L. japonica and M. aeruginosa co-cultivation demonstrated a 50\% reduction in plant biomass compared to controls. The above results may suggest differences in the sensitivity of both Lemna species to the cyanobacterial toxins. Besides, the growth rate of $L$. japonica could be inhibited by microcystin (MC), a toxin produced by M. aeruginosa with a chemical structure and mechanism of action significantly different from CYN.

\section{Concentration of CYN in medium, plants tissues and cyanobacterial cells}

It was shown that long-term (35 days) cultivation of $R$. raciborskii with $L$. trisulca led to a decrease in CYN concentration in the media and cyanobacterial cells compared to the values obtained for separate cultivation of cyanobacteria (Figs. 3 and 5). The reduction in toxin concentration in these media might be the result of an increase in the $\mathrm{pH}$ value to 10 (Fig. 6). This conclusion is supported by the documented decomposition of CYN under $\mathrm{pH} \geq 10$ (Chiswell et al. 1999; Adamski et al. 2016). Besides, in the media where the cyanobacterium was grown itself for a similar time, the $\mathrm{pH}$ increased only to 9. Inhibition of CYN 
synthesis by $R$. raciborskii, and thus the reduction of its amount in the cells after cultivation with $L$. trisulca might be associated with changes in the concentration of mineral components in the media due to the presence of macrophyte (Figs. 7 and 8). This process has been confirmed in a natural environment where the availability of minerals had a significant impact on the production of toxins by different types of cyanobacteria (Saker and Neilan 2001; Bar-Yosef et al., 2010). In contrast, Kearns and Hunter (2000) indicated that the presence of Chlamydomonas reinhardtii algae stimulated anatoxin-a (ANTX-a) synthesis by A. flos-aquae during their co-cultivation. Similar results were obtained by Jang et al. (2007), who demonstrated that 12 days cultivation of $L$. japonica with $M$. aeruginosa caused an increase in the intra- and extracellular concentration of MC. However, similarly to CYN, this toxin has not been identified in macrophyte tissues. Increased MC production likely exerted an allelopathic effect on the studied macrophyte by inhibiting its growth (Jang et al. 2007).

\section{Changes in the concentration of nitrate and phosphate ions}

Excessive absorption of phosphate ions by L. trisulca (Fig. 8) compared to nitrate ions (Fig. 7) during cultivation with cyanobacterium led to a significant increase in the N:P ratio in the media. This was contributed to the effective inhibition of $R$. raciborskii growth rate after 35 days of the experiment. Furthermore, no changes in the N:P ratio were observed for independent cultivation of cyanobacteria. Similar results were shown by Kaminski et al. (2015). L. trisulca cultivated separately and together with A. flosaquae caused a significant increase in the $\mathrm{N}: \mathrm{P}$ ratio. However, in case of co-cultivation of $L$. japonica with $M$. aeruginosa such changes were not observed (Jang et al. 2007). Based on the above results, it can be assumed that $L$. trisulca in the natural environment affects the development and physiology of cyanobacteria.

\section{Conclusion}

Cyanobacteria synthesizing toxic secondary metabolites in the aquatic environments constantly compete with other species of cyanobacteria, algae and macrophytes. The main role of cyanobacterial toxins in ecosystems is attributed to the function of the allelopathic interaction with other co-existing organisms (Holland and Kinnear, 2013). This is the first report presenting the results of interaction between $L$. trisulca and $R$. raciborskii during co-cultivation. Our results revealed a decrease in CYN production and growth rate inhibition of $R$. raciborskii upon long-term exposure to L. trisulca. It suggests that unknown compounds released by this macrophyte might perform the function as allelochemicals, which in the natural environment can effectively inhibit the development of toxic cyanobacterial blooms.

\section{Data availability}

All data generated during this study are included in the article.

Acknowledgements We are grateful to Professor Zbigniew Lechowski for his constructive helpful comments and assistance.

Author contributions K.D., J.B. and E.C.-S. designed the study. K.D. performed the experiments and prepared draft of manuscript. K.D. analysed and interpreted of the data. K.D., J.B., E.C.-S. and B.B. reviewed and edited the manuscript.

\section{Compliance with ethical standards}

Conflict of interest The authors declare no competing interests.

Publisher's note Springer Nature remains neutral with regard to jurisdictional claims in published maps and institutional affiliations.

Open Access This article is licensed under a Creative Commons Attribution 4.0 International License, which permits use, sharing, adaptation, distribution and reproduction in any medium or format, as long as you give appropriate credit to the original author(s) and the source, provide a link to the Creative Commons license, and indicate if changes were made. The images or other third party material in this article are included in the article's Creative Commons license, unless indicated otherwise in a credit line to the material. If material is not included in the article's Creative Commons license and your intended use is not permitted by statutory regulation or exceeds the permitted use, you will need to obtain permission directly from the copyright holder. To view a copy of this license, visit http://creativecommons. org/licenses/by/4.0/.

\section{References}

Adamski M, Zmudzki P, Chrapusta E, Bober B, Kaminski A, Zabaglo $\mathrm{K}$, Bialczyk J (2016) Effect of $\mathrm{pH}$ and temperature on the stability of cylindrospermopsin. Characterization of decomposition products. Algal Res 15:129-134. https://doi.org/10.1016/j.algal.2016.02.020

Bar-Yosef Y, Sukenik A, Hadas O, Viner-Mozzini Y, Kaplan A (2010) Enslavement in the water body by toxic Aphanizomenon ovalisporum, inducing alkaline phosphatase in phytoplanktons. Curr Biol 20(17):1557-1561. https://doi.org/10.1016/j.cub.2010.07.032

Caraco NF, Cole JJ (2002) Contrasting impacts of a native and alien macrophyte on dissolved oxygen in a large river. Ecol Appl 12 (5):1496-1509. https://doi.org/10.1890/1051-0761(2002)012 [1496:CIOANA]2.0.CO;2

Chiswell RK, Shaw GR, Eaglesham GK, Smith MJ, Norris RL, Seawright AA, Moore MR (1999) Stability of cylindrospermopsin., the toxin from the cyanobacterium Cylindrospermopsis raciborskii, effect of $\mathrm{pH}$, temperature, and sunlight on decomposition. Environ Toxicol 14:155-165. https://doi.org/10.1002/(SICI) 1522-7278(199902)14:1

Dziga D, Suda M, Bialczyk J, Czaja-Prokop U, Lechowski Z (2007) The alteration of Microcystis aeruginosa biomass and dissolved 
microcystin-LR concentration following exposure to plantproducing phenols. Environ Toxicol 22:341-346. https://doi. org/10.1002/tox.20276

Flores-Rojas NC, Esterhuizen-Londt M, Pflugmacher S (2015) Antioxidative stress responses in the floating macrophyte Lemna minor L. with cylindrospermopsin exposure. Aquat Toxicol 169:188-195. https://doi.org/10.1016/j.aquatox.2015.11.002

Gross E (1999) Allelopathy in benthic and littoral areas: case studies on allelochemicals from benthic cyanobacteria and submersed macrophytes. In: K. M. M. Inderjit, Dakshini, C.L. Foy (eds) Principles and practices in plant ecology: allelochemical interactions. CRL Press, Boca Raton, pp. 179-199

Hang LIZ (2017) Short communication Allelopathic activity of ethyl acetate extracts from typical emergent plants against Microcystis aeruginosa KUTZ. Bangladesh J Bot 46:1025-1029

Holland A, Kinnear S (2013) Interpreting the possible ecological role (s) of cyanotoxins: compounds for competitive advantage and/or physiological aide? Mar Drugs 11(7):2239-2258. https://doi.org/ 10.3390/md11072239

Hong Y, Hu HY, Li FM (2008) Physiological and biochemical effects of allelochemical ethyl 2-methyl acetoacetate (EMA) on cyanobacterium Microcystis aeruginosa. Ecotoxicol Environ Saf 71 (2):527-534. https://doi.org/10.1016/j.ecoenv.2007.10.010

Hong Y, Hu HY, Xie X, Sakoda A, Sagehashi M, Li FM (2009) Gramine-induced growth inhibition, oxidative damage and antioxidant responses in freshwater cyanobacterium Microcystis aeruginosa. Aquat Toxicol 91:262-269. https://doi.org/10.1016/j. aquatox.2008.11.014

Hong Y, Hu HY, Sakoda A, Sagehashi M (2011) Straw preservation effects of Arundo donax L. on its allelopathic activity to toxic and bloom-forming Microcystis aeruginosa. Water Sci Technol 63 (8):1566-1573. https://doi.org/10.2166/wst.2011.209

Hua Q, Liu YG, Yan ZL, Zeng GM, Liu SB, Wang WJ (2018) Allelopathic effect of the rice straw aqueous extract on the growth of Microcystis aeruginosa. Ecotox Environ Safe 148:953-959. https://doi.org/10.1016/j.ecoenv.2017.11.049

Jang MH, Ha K, Takamura N (2007) Reciprocal allelopathic responses between toxic cyanobacteria (Microcystis aeruginosa) and duckweed (Lemna japonica). Toxicon 49(5):727-733. https://doi. org/10.1016/j.toxicon.2006.11.017

Kaminski A, Chrapusta E, Bober B, Adamski M, Latkowska E, Bialczyk J (2015) Aquatic macrophyte Lemna trisulca (L.) as a natural factor for reducing anatoxin-a concentration in the aquatic environment and biomass of cyanobacterium Anabaena flosaquae (Lyngb.) de Bréb. Algal Res 9:212-217. https://doi.org/10. 1016/j.algal.2015.03.014

Kang P, Hong J, Kim E, Kim B (2020) Effects of extracts of reed and cattail on the growth of a cyanobacterium, Microcystis aeruginosa. Freshwater Ecol 35:123-134. https://doi.org/10.1080/ 02705060.2020 .1748128

Kearns KD, Hunter MD (2000) Green algal extracellular products regulate antialgal toxin production in a cyanobacterium. Environ Microbiol 2:291-297. https://doi.org/10.1046/j.1462-2920.2000. 00104.x

Kleinteich J, Hildebrand F, Wood SA, Ciŕs S, Agha R, Quesada A, Dietrich DR (2014) Diversity of toxin and non-toxin containing cyanobacterial mats of meltwater ponds on the Antarctic Peninsula: a pyrosequencing approach. Ant Sci 26(5):521-532. https:// doi.org/10.1017/S0954102014000145

Lankoff A, Wojcik A, Lisowska H, Bialczyk J, Dziga D, Carmichael WW (2007) No induction of structural chromosomal aberrations in cylindrospermopsin-treated $\mathrm{CHO}-\mathrm{K} 1$ cells without and with metabolic activation. Toxicon 50:1105-1115. https://doi.org/10. 1016/j.toxicon.2007.07.021

Leu E, Krieger-Liszkay A, Goussias C, Gross EM (2002) Polyphenolic allelochemicals from the aquatic angiosperm Myriophyllum spicatuminhibit photosystem II. Plant Physiol 130(4):2011-2018. https://doi.org/10.1104/pp.011593

Lu Z, Zhang Y, Gao Y, Liu B, Sun X, He F, Zhou Q, Wu Z (2016) Effects of pyrogallic acid on Microcystis aeruginosa: oxidative stress related toxicity. Ecotox Environ Safe 132:413-419. https:// doi.org/10.1016/j.ecoenv.2016.06.039

Meriluoto J, Codd GA (2005) TOXIC: cyanobacterial monitoring and cyanotoxin analysis. Åbo Akademi University Press, Åbo, Finland, 119-133

Mohamed ZA (2017) Macrophytes-cyanobacteria allelopathic interactions and their implications for water resources managementa review. Limnologica 63:122-132. https://doi.org/10.1016/j. limno.2017.02.006

Mowe MA, Song Y, Sim DZ, Lu J, Mitrovic SM, Tan HT, Yeo DC (2019) Comparative study of six emergent macrophyte species for controlling cyanobacterial blooms in a tropical reservoir. Ecol Eng 129:11-21. https://doi.org/10.1016/j.ecoleng.2018.12.026

Mulderij G, Mau B, Van Donk E, Gross EM (2007) Allelopathic activity of Stratiotes aloides on phytoplankton-towards identification of allelopathic substances. Hydrobiologia 584:89-100. https://doi.org/10.1007/s10750-007-0602-0

Nakai S, Inoue Y, Hosomi M, Murakami A (1999) Growth inhibition of blue-green algae by allelopathic effects of macrophytes. Water Sci Technol 39(8):47-53. https://doi.org/10.2521/jswtb.33.215

Nakai S, Inoue Y, Hosomi M, Murakami A (2000) Myriophyllum spicatum-released allelopathic polyphenols inhibiting growth of blue-green algae Microcystis aeruginosa. Water Res 34:3026-3032. https://doi.org/10.1016/S0043-1354(00)00039-7

Nakai S, Zou G, Okuda T, Nishijima W, Hosomi M, Okada M (2012) Polyphenols and fatty acids responsible for anti-cyanobacterial allelopathic effects of submerged macrophyte Myriophyllum spicatum. Water Sci Technol 66(5):993-999. https://doi.org/10. 2166/wst.2012.272

Norris RL, Seawright AA, Shaw GR, Smith MJ, Chiswell RK, Moore MR (2001) Distribution of 14C-cylindrospermopsin in vivo in the mouse. Environ Toxicol 16:498-505. https://doi.org/10.1002/tox. 10008

Pflugmacher S (2002) Possible allelopathic effects of cyanotoxins, with reference to microcystin-LR, in aquatic ecosystems. Environ Toxicol 17(4):407-413. https://doi.org/10.1002/tox.10071

Pott VJ, Pott A (2003) Dinâmica da vegetação aquática do Pantanal. Ecol. Man Macróf Aquát 1. In: Thomaz SM, Bini LM (eds) Ecologia e manejo de macrófitas aquáticas. Editora da Universidade Estadual de Maringá, Maringá, Brasil (in Portuguese). pp. 145-162

Rippka R, Deruelles J, Waterbury JB, Herdman M, Stanier RY (1979) Generic assignments, strain histories and properties of pure cultures of cyanobacteria. Microbiology 111(1):1-61. https://doi. org/10.1099/00221287-111-1-1

Rojo C, Segura M, Rodrigo MA (2013) The allelopathic capacity of submerged macrophytes shapes the microalgal assemblages from a recently restored coastal wetland. Ecol Eng 58:149-155. https:// doi.org/10.1016/j.ecoleng.2013.06.019

Rzymski P, Poniedziałek B (2014) In search of environmental role of cylindrospermopsin: a review on global distribution and ecology of its producers. Water Res 66:320-337. https://doi.org/10.1016/ j.watres.2014.08.029

Saker ML, Neilan BA (2001) Varied diazotrophies, morphologies, and toxicities of genetically similar isolates of Cylindrospermopsis raciborskii (Nostocales, Cyanophyceae) from northern Australia. Appl Environ Microbiol 67(4):1839-1845. https://doi.org/10. 1128/AEM.67.4.1839-1845.2001

Santos C, Azevedo J, Campos A, Vasconcelos V, Pereira AL (2015) Biochemical and growth performance of the aquatic macrophyte Azolla filiculoides to sub-chronic exposure to cylindrospermopsin. Ecotoxicology 24(9):1848-1857. https://doi.org/ 10.1007/s10646-015-1521-x 
Tazart Z, Douma M, Tebaa L, Loudiki M (2019) Use of macrophytes allelopathy in the biocontrol of harmful Microcystis aeruginosa blooms. Water Supply 19(1):245-253. https://doi.org/10.2166/w s.2018.072

Tazart Z, Caldeira AT, Douma M, Salvador C, Loudiki M (2020). Inhibitory effect and mechanism of three macrophytes extract on Microcystis aeruginosa growth and physiology. Water Environ J. https://doi.org/10.1111/wej.12653

Terao K, Ohmori S, Igarishi K, Ohtani I, Watanabe MF, Harada KI, Ito E, Watanabe M (1994) Electron microscope studies on experimental poisoning in mice induced by cylindrospermopsin isolated from blue-green alga Umezekia natans. Toxicon 32:833-843. https://doi.org/10.1016/0041-0101(94)90008-6

Zhang S (2015) Allelopathic activities of three emergent macrophytes on several monospecific cyanobacterial species and natural phytoplankton assemblages. Pol J Enviro Stud 24:397-402. https:// doi.org/10.15244/pjoes/26972

Zhu J, Liu B, Wang J, Gao Y, Wu Z (2010) Study on the mechanism of allelopathic influence on cyanobacteria and chlorophytes by submerged macrophyte (Myriophyllum spicatum) and its secretion. Aquat Toxicol 98(2):196-203. https://doi.org/10.1016/j. aquatox.2010.02.011 